\title{
O ESTUDO DO DIREITO ADMINISTRATIVO COMO LINGUAGEM
}

\author{
THE STUDY OF ADMINISTRATIVE LAW AS LANGUAGE
}

Flávio Garcia Cabral ${ }^{1}$

\section{RESUMO}

Este trabalho versa sobre a relação entre o Direito Administrativo e a linguagem. Pretendese, com a análise a ser feita, compreender a importância da linguagem para o conhecimento científico, em particular o do Direito, bem como demonstrar sua utilidade para o estudo do Direito Administrativo. Para a realização deste artigo, utiliza-se o método de abordagem dedutivo, possuindo natureza descritiva e exploratória quanto aos fins e bibliográfica no que se refere aos meios. Ao final, apura-se que o Direito deve ser encarado como linguagem e, portanto, permite a utilização de instrumentos linguísticos para sua interpretação/aplicação. Verifica-se que existem inúmeros aspectos do Direito Administrativo que podem ser encarados sob essa perspectiva linguística, lançando novas formas de interpretação normativa, além de conferir maior objetividade ao intérprete. Com a análise, abre-se um leque de novas possibilidades de investigação do Direito Administrativo, seja para confirmar ou infirmar estudos antes consolidados.

Palavras-Chave: Giro-linguístico; Linguagem; Semiótica; Direito Administrativo; Interpretação.

\begin{abstract}
This paper deals with the relationship between Administrative Law and language. The aim of the analysis is to understand the importance of the language for scientific knowledge, in particular the Law, as well as demonstrate its usefulness for the study of Administrative Law. For the accomplishment of this paper, the method of deductive approach is used, having descriptive and exploratory nature regarding the ends and bibliographical regarding the means. In the end, it is established that the Law should be considered as language and, therefore, allows the use of linguistic instruments for its interpretation/application. There are many aspects of Administrative Law that can be approached from this linguistic perspective, introducing new forms of normative interpretation, in addition to giving greater accuracy to the interpreter. With the analysis, a range of new possibilities to investigate Administrative Law is opened, either to confirm or to refute previously consolidated studies.
\end{abstract}

Keywords: Linguistic turn; Language; Semiotics; Administrative law; Interpretation.

1 Pós-Doutorando pela PUC-PR; Doutor em Direito Administrativo pela PUC/SP; Mestre em Direito Constitucional e Teoria do Estado pela PUC/RJ; Mestre em Direito pela Universitat de Girona-Espanha; Especialista em Direito Administrativo pela PUC/SP; Professor universitário; Procurador da Fazenda Nacional, atualmente exercendo a função de Procurador-Chefe da Fazenda Nacional em Mato Grosso do Sul. UNIGRAN/MS e EDAMP/MS - Brasil. Lattes: http://lattes.cnpq.br/6700366828354028 E-mail: flaviocabral_@hotmail.com 


\section{INTRODUÇÃO}

O estudo do Direito Administrativo no Brasil já possui mais de século, tendo-se criado a cadeira desta disciplina nos cursos jurídicos já na época imperial, podendo-se mencionar a criação da cadeira em Olinda em 1851 ou em São Paulo em 1856. Desde então muito já se escreveu e pesquisou a respeito deste ramo jurídico que versa sobre o estudo da função administrativa, havendo inúmeras correntes e obras doutrinárias, escolas de pensamento com características próprias, desde visões que focavam nas prerrogativas estatais até uma escola do Direito Administrativo Social.

Não obstante a larga evolução e construção jurídica envolvendo a disciplina administrativista, ainda é possível se pensar, desde que haja utilidade, em novas formas de pesquisa e estudo deste ramo. Uma delas, que tem se mostrado promissora em outros campos do conhecimento e até mesmo em determinados ramos do Direito, reside na utilização da filosofia da linguagem para a pesquisa do fenômeno jurídico.

O problema repousa justamente no aparente desconhecimento da doutrina acerca da inter-relação entre o Direito Administrativo e a linguagem, havendo escassos trabalhos que fazem esse destaque ou mesmo que, ainda que de maneira não expressa, valem-se dos instrumentos ofertados pela linguística.

Assim, pretende-se, nas linhas tracejadas adiante, compreender a importância da linguagem para o conhecimento científico, em particular o do Direito, bem como demonstrar sua utilidade para o estudo do Direito Administrativo.

Este ensaio estrutura-se em duas partes: na primeira, aborda-se a questão da importância da linguagem para o conhecimento, destacando-se o movimento girolinguístico, a relação entre Direito e linguagem e a utilização dos planos semióticos para a pesquisa.

No segundo momento, foca-se no escopo principal do trabalho, qual seja, apontar as imbricações entre o Direito Administrativo e a linguagem, apresentando uma série de situações nas quais essa conexão ocorre.

Para a realização deste paper, utiliza-se o método de abordagem dedutivo, possuindo natureza descritiva e exploratória quanto aos fins e bibliográfica no que se refere aos meios. 


\section{CONHECIMENTO E LINGUAGEM}

Até tempos mais recentes, a linguagem ${ }^{2}$ jamais havia ocupado o ponto central do pensamento filosófico ocidental. Em que pese a força religiosa que parecia encaminhar para esse desfecho, ao narrar pelas escrituras que Deus ordenou ao primeiro homem que nomeasse as coisas do mundo ou o relato da fundamentalidade da linguagem com a Torre de Babel, houve uma paralisação na consideração da linguagem pelo menos até o Iluminismo, momento no qual se retomou a busca pela sua origem (GADAMER, 1998, p.146).

É justamente no aflorar do Renascimento, com a difusão da escrita, que a linguagem volta a assumir certo grau de destaque. A imprensa, a chegada à Europa dos manuscritos orientais, o aparecimento de uma literatura que não era mais feita pela voz ou pela representação nem comandada por elas, "a primazia dada à interpretação dos textos religiosos sobre a tradição e o magistério da igreja - tudo isso testemunha, sem que se possam apartar os efeitos e as causas, o lugar fundamental assumido, no Ocidente, pela Escrita" (FOUCAULT, 1999, p.52).

A linguagem e sua relação com o mundo vão cambiando ao longo dos séculos. Como nos serve Michel Foucault (1999, p.58), na Antiguidade se perguntava como reconhecer que um signo designasse realmente aquilo que ele significava. Posteriormente, a partir do século XVII, perguntar-se-á como um signo pode estar ligado àquilo que ele significa. Para dito questionamento, a idade Clássica responderá pela análise da representação; por sua vez, o pensamento moderno contestará pela análise do sentido e da significação.

A maior cientificação da linguagem, tornando-a não só instrumento, mas sim o próprio objeto do conhecimento, toma lugar na transição do século $\mathrm{XIX}^{3}$ para o século $\mathrm{XX}$,

\footnotetext{
${ }^{2}$ Ferdinand de Saussure (2004, p.119) diferencia linguagem e língua explicando que a primeira é um fenômeno, o exercício de uma faculdade no homem. Língua é um conjunto de formas que toma esse fenômeno (linguagem) em uma coletividade de indivíduos e em uma época determinada. Aurora Tomazini de Carvalho (2013, p.162163) traz uma terceira figura próxima: a fala. Para a autora, "enquanto a língua caracteriza-se como uma instituição social, depositada no nosso inconsciente dentro de um processo histórico-evolutivo, a fala tem caráter pessoal, ela traz consigo a 'individualidade' manifesta nas escolhas daquele que se utiliza da língua. A língua é algo estático que se movimenta (transforma) por meio da fala. Já a fala é algo dinâmico, ela é a língua em movimento". Em tom de síntese: "Neste sentido, língua, fala e linguagem são conceitos conexos, tão interligados que por vezes utilizamos o termo 'linguagem' para referirmo-nos tanto à língua, quanto à fala. Mas, por apreço à diferenciação, em termos mais simples, sintetiza-se que a língua é a linguagem sem a fala e a fala é a linguagem sem a língua".

3 "O conhecimento clássico era profundamente nominalista. A partir do século XIX, a linguagem se dobra sobre si mesma, adquire sua espessura própria, desenvolve uma história, leis e uma objetividade que só a ela pertencem" (FOUCAULT, 1999, p.408).
} 
com pesquisas atinentes à agora chamada filosofia da linguagem, ${ }^{4}$ destacando-se trabalhos de Frege, Russell, Saussure, Pierce, Wittgenstein, Bakhtin, dentre outros filósofos da modernidade.

Nessa história surgem dois momentos diversos, como narra Luis Alberto Warat (1995, p.11): o primeiro, intencionado a superar essa instância pré-científica das reflexões sobre a linguagem, e o segundo, que busca projetar o conhecimento científico dos signos sobre as ciências sociais, permitindo que a abordagem linguística fosse o marco teórico das ciências humanas.

Assim, "com a literatura, com o retorno da exegese e a preocupação da formalização, com a constituição de uma filologia, em suma, com o reaparecimento da linguagem num pulular múltiplo, a ordem do pensamento clássico pode doravante apagar-se" (FOUCAULT, 1999, p.417). Vivencia-se, pois, um novo marco filosófico que permeia as mais diversas ciências na modernidade, tendo como pilar fundante a própria linguagem.

\subsection{Movimento Giro-Linguístico}

Como adiantado, o papel desempenhado pela linguagem na construção do conhecimento figurou durante a história da filosofia ocidental essencialmente em termos instrumentais e acessórios.

A ciência do conhecimento foi marcada, entre suas várias fases, na sua busca por intermédio da percepção de que conhecer se referia a uma relação entre sujeito e objeto ${ }^{5}$, com a ideia de objetificação, isto é, reproduzia-se intelectualmente o real.

Essa concepção, expõe Aurora Tomazini de Carvalho (2013, p.14), tanto partia das perspectivas do sujeito (gnosiologia), como do objeto (ontologia) ou da relação entre ambos (fenomenologia), assumindo a linguagem um mero papel coadjuvante.

Tinha-se assim um paradigma epistemológico da filosofia da consciência, fundada na premissa dos sujeitos cognoscentes, na qual as formas de vida e relacionamentos são reificadas, limitando-se às relações sujeito-objeto (STRECK, 1999, p.44).

\footnotetext{
${ }^{4}$ Didaticamente, Cláudio Costa (2007, p.7-8) expõe duas significações para filosofia da linguagem: a primeira, de cunho mais estrito, seria o resultado de uma investigação filosófica acerca da natureza e do funcionamento da linguagem, também chamada de "análise da linguagem"; a segunda, mais ampla, diz respeito a qualquer abordagem crítica de problemas filosóficos, metodologicamente orientada por uma investigação da linguagem ("crítica da linguagem").

5 "É possível dizer que, para a metafísica clássica, os sentidos estavam nas coisas (as coisas têm sentido porque há nelas uma essência). Essa é a dicotomia objetivismo-subjetivismo, presente e influente nas teorias que buscam explicar o modo como conhecemos e compreendemos o mundo" (STRECK, 2017, p.85).
} 
É, inclusive, como nos dá conta Robson Maia Lins (2014, p.176), explicando que com a filosofia da consciência, afirmava-se que as coisas tinham existência empírica. Desse modo, partindo-se de considerações kantianas, o limite do conhecimento era imposto tanto pelo pensamento como pela experiência, sendo que a linguagem, que aparecia em ambos os momentos, era meramente instrumental, ligando o sujeito ao objeto do conhecimento.

Como visto, é somente no final do século $\mathrm{XIX}^{6}$ e início do século XX, contudo, com o desenvolvimento de sistemas lógicos e por meio do papel pioneiro desempenhado pelos filósofos anglo-saxões e os positivistas austro-alemães (Círculo de Viena), ${ }^{7}$ que a linguagem se torna um dos elementos essenciais das reflexões filosóficas (AUROUX, 1998, p.431).

Justamente nessa nova vertente filosófica, em especial com Ludwig Wittgenstein e sua obra Tractatus Logico-Philosophicus, é que emerge uma nova corrente filosófica que põe em xeque certas premissas pensadas anteriormente.

É na supracitada obra que Ludwig Wittgenstein ${ }^{8}(1968$, p.111) molda a celebre frase "os limites de minha linguagem denotam os limites de meu mundo" e volta a insisti-la nos trechos em que diz "que o mundo é o meu mundo, isto se mostra porque os limites da linguagem (da linguagem que só eu compreendo) denotam os limites do meu mundo" e "o sujeito não pertence ao mundo mas é o limite do mundo".

A grande marca dessa nova teoria do conhecimento é a mudança de paradigma no que se refere à linguagem. $\mathrm{O}$ conhecimento agora não mais representa uma relação entre sujeito e objeto, mas sim entre linguagens, entre significações (LINS, 2014, p.177). Para

\footnotetext{
6 "Although philosophers have long speculated about language, it wasn't until the late nineteenth century that the philosophy of language emerged as a self-conscious and systematic area of study" (SOAMES, 2010, p.7). ${ }^{7}$ Sobre a formação do Círculo de Viena, confira-se breve narrativa de Paulo de Barros Carvalho (2013, p.22): "Desde os idos de 1907, Hans Hahn, Phillipp Frank e Otto Neurath encontravam-se, constantemente, num determinado café vienense, com o objetivo de trocar ideias a respeito de temas ligados à Filosofia da Ciência. Entretanto, foi com a vinda de Moritz Schlick para a capital austríaca, transferindo-se de Kiel, nomeado para ocupar a cátedra de Filosofia das Ciências Indutivas, que se pôde reconhecer, efetivamente, a gênese do chamado 'Círculo de Viena'. Schlick obtivera o doutoramento em Berlim, com tese sobre a Óptica teórica, orientado por Max Planck. Iniciou seu magistério em Viena em 1922, mas logo no ano seguinte coordenava um seminário, no seio do qual surgiu o famoso grupo de debates, integrado por filósofos e cientistas dos mais variados campos e dotados, todos eles, de inusitado interesse por temas epistemológicos, passando a reunir-se, com habitualidade, às senoites das quintas-feiras".

${ }^{8}$ Para quem estuda e acompanha os estudos de Ludwig Wittgenstein, costuma-se dividir seus escritos em duas fases, sendo o "Tractatus Logico-Philosophicus" considerado o primeiro Wittgenstein e suas obras futuras, em especial o seu "Investigações Filosóficas", o segundo Wittgenstein. Embora tenha havido uma profunda mudança na visão da linguagem do autor do primeiro para o segundo Wittgenstein, isso não retira a importância das primeiras conclusões, em especial pelo fato do próprio autor não ter considerado errôneas suas primeiras reflexões, mas simplesmente incapazes de solucionar todos os dilemas trazidos pela linguagem. Nesse segundo momento, não se deve mais indagar sobre o significado das palavras de forma absoluta, mas sim sobre seus usos, ao que denomina de "jogos de linguagem". Para o autor, todo o processo da utilização das palavras na práxis do uso da linguagem é um "daqueles jogos por meio dos quais as crianças aprendem sua língua materna". Apresenta mais a frente que "a significação de uma palavra é seu uso na linguagem" (WITTGENSTEIN, 1999, p.30; 43).
} 
Jürgen Habermas (2000, p.414) “o que está esgotado é o paradigma da filosofia da consciência". Continua o autor dizendo que "se procedermos assim, certamente devem se dissolver os sintomas de esgotamento na passagem para o paradigma do sentimento recíproco".

Justamente por se trabalhar o conhecimento em bases sustentadas pela relação sujeito e objeto, em uma perspectiva essencialmente empírica e com verificações de cunho quase que exclusivamente apofântico, as ciências lidavam com verdades tidas como absolutas, nas quais a comprovação das asserções correspondia à verificação entre a afirmação (linguagem) e a constatação ontológica.

Com essa virada filosófica, conhecida como giro-linguístico, virada linguística, linguistic turn, dentre outras denominações, não se mostra mais possível lidar com uma verdade absoluta, ${ }^{9}$, tampouco há que se falar em verdade no singular, havendo uma multiplicidade de verdades.

Deveras, o conhecimento de cada sujeito se molda em consonância com um sistema de referências condicionado por seus horizontes culturais. Destarte, não faz mais sentido discursar acerca de verdades absolutas, próprias de um objeto, já que o mesmo dado experimental comporta inúmeras interpretações. A verdade é, portanto, uma característica da linguagem, determinada em concordância com o modelo adotado, pelas condições de espaço-tempo, além da vivência sócio-cultural de uma língua. Conclui-se, pois, que é sempre relativa (CARVALHO AT, 2013, p.26).

Conforme essa nova percepção, ${ }^{10}$ descarta-se aquele paradigma ontológico, no qual as palavras correspondiam a dados existentes na realidade, para se afirmar que são elas que cunham a própria realidade. Vilém Flusser (2004, p.46), expoente da Filosofia da Linguagem, dispõe que "a matéria-prima do intelecto, a realidade, portanto, consiste de palavras e de dados brutos a serem transformados em palavras a serem apreendidos e compreendidos".

A linguagem como mera correspondência entre palavras e objetos, algo até então intuitivo em uma filosofia de cunho ontológico, não mais satisfaz as pretensões desse novo conhecimento, tampouco reflete uma desinteressada percepção da consciência, como

\footnotetext{
9 “A verdade absoluta, essa correspondência entre a língua e o 'algo' que ela significa, é tão inarticulável quanto esse 'algo"” (FLUSSER, 2004, p.46).

10 “Crecemos, vamos conociendo el mundo, vamos conociendo a las personas y en definitiva a nosotros mismos a medida que aprendemos a hablar. Aprender a hablar no significa utilizar un instrumento ya existente para clasificar ese mundo familiar y conocido, sino que significa la adquisición de la familiaridad y conocimiento del mundo mismo tal como nos sale al encuentro" (GADAMER, 1998, p.148).
} 
propunha a própria filosofia do sujeito ou da consciência. Linguagem reflete linguagem, cunhando o que temos por realidade.

\subsection{Direito e Linguagem}

Como se pode sentir das linhas construídas nos itens anteriores, enxerga-se que o movimento denominado giro-linguístico trouxe considerações de grande valia para o pensamento filosófico contemporâneo, acolhendo-se neste trabalho suas premissas essenciais, em especial as observações da linguagem como constitutiva da realidade e a inoponível apuração de que tanto a Ciência do Direito como o direito posto se formam por meio de um conjunto de signos devidamente dispostos (linguagem).

Com isso não se quer abandonar o Direito, deve-se ressalvar. A esse respeito, as palavras de Tércio Sampaio Ferraz Júnior (2006, p.7-8) explicam de maneira clara essa interrelação entre Direito e linguagem:

[...] pretendemos estudar a linguagem do direito ou da sua manifestação normativa, mas investigar o próprio direito, enquanto necessita, para a sua existência, da linguagem. Ou seja, o direito é levado ao nível linguístico, mas o estudo a realizar não é de linguistica, mas jurídico, pois não dispensamos, ao investigar a norma, as características operacionais da teorização jurídica, como a referência à práxis decisória, a possibilidade de solução de conflitos, a regulamentação de comportamentos, etc.

O Direito se aproveita da circunstância de ser visto como linguagem para colher métodos de análise oriundos da linguística e, ele próprio, só existe e funciona por meio da linguagem.

Destarte, no Direito a linguagem estabelece relações entre pessoas e grupos sociais, ocasionando o surgimento/desaparecimento de entidades, concede e usurpa a liberdade, absolve e condena réus. Um compromisso, antes inexistente, passa a existir no Direito pelo uso da linguagem; um novo órgão ou entidade estatal surge pela utilização da linguagem correta pela autoridade correta. Enfim, qualquer alteração no mundo do Direito ocorre porque foi realizado um ato jurídico por intermédio de um ato de fala: realiza-se um ato performativo de fala, uma ação que determina mudanças no mundo legalmente estruturado (COLARES, 2010, p.10).

O Direito, insista-se, mostra-se indissociável da linguagem, uma vez que é por meio desta que ele se constitui. É somente mediante atos específicos de fala que os textos jurídicos 
são inseridos ao sistema jurídico e as normas jurídicas em sentido estrito são construídas pelos intérpretes. Não há nenhum fragmento do Direito que não seja expresso por uma linguagem própria (CABRAL, 2015, p.141).

A percepção do Direito como constituído por linguagem permite, a nosso ver, um estudo mais coerente e com menos arestas a serem aparadas, ademais de conferir uma maior autonomia ao sistema jurídico, que se configura como uma ordem constituída por linguagem própria.

\subsection{Elementos da Semiótica}

Justamente por se verificar a linguagem como constitutiva da realidade e, em específica aproximação com o Direito, que este se forma por um conjunto de símbolos artificiais, permitiu-se que o estudo jurídico passasse a ser efetuado por diferentes abordagens metodológicas que levassem essas circunstâncias em consideração.

Aqui, nada mais coerente que, ao partir da premissa do Direito positivo como um conjunto de signos, tal objeto seja passível de ser investigado por meio de instrumentos advindos dos estudos linguísticos. Afinal de contas, tanto se fala do Direito por meio de linguagem (Ciência do Direito), como o próprio Direito positivo é por ela formado. ${ }^{11}$

Nos dizeres de Clarice Von Oertzen de Araujo (2005, p.15), o Direito visto em sua interdisciplinariedade com o verbal facilita seus estudos iniciais "porque empresta da língua conceitos correntes que se encontram também na organização das normas". Ainda, "introduz o pensamento jurídico, enfatiza o domínio verbal e exercita a interface nas áreas de afinidade entre os sistemas".

A proposta sugerida não implica o abandono da Ciência do Direito, mas sim a promoção de um autêntica intertextualidade externa, que não debilita as margens do Direito ou compromete sua interioridade (IVO, 2006, p.XLIV).

Com esse espírito, a semiótica, que tem grandes expoentes como Peirce, Saussure, Morris, Carnap, entre outros, representa interessante instrumento a ser invocado para a compreensão dos signos.

As exposições usuais dessa disciplina se fundam em especial nas lições de Ferdinand de Saussure, com o desenvolvimento de uma Semiologia (hoje chamada de semiótica) e do

\footnotetext{
11 Tem-se aqui a metalinguagem, havendo dois substratos linguísticos diversos, um de caráter prescritivo (Direito positivo) e outro de caráter descritivo em relação ao direito posto (Ciência do Direito).
} 
filósofo pragmatista Charles S. Pierce, que pesquisou a semiótica buscando as condições que uma asserção deve possuir para que corresponda à realidade (AFTALIÓN; VILANOVA; RAFFO, 2004, p.79).

Em amplos termos, propõe a semiótica o estudo de todos os processos culturais como sendo processos de comunicação (ECO, 1979, p.8).

Outra forma de se compreender a semiótica, mais especifica, é a trazida por Charles W. Morris (1938, p.3), o qual explana que ela é a ciência que estuda a semiose, que representa o processo no qual algo funciona como um sinal. Esse processo, que remonta aos gregos, comumente sempre foi trabalhado com o envolvimento de três ou quatro fatores: a) sign vehicle (aquilo que age como um sinal); b) designatum (aquilo a que o sinal se refere); c) interpretant (aquele efeito gerado no intérprete em virtude do sinal que lhe é apresentado); d) interpreter (o próprio intérprete).

Justamente buscando lidar nos arredores dos aludidos fatores semióticos, uma divisão valiosa trazida a essa área do conhecimento, de cunho didático, pode ser atribuída a Charles W. Morris (1938, p.6-9), ${ }^{12}$ que repartiu o estudo semiótico nas análises do campo da sintática, semântica e pragmática.

\subsubsection{Plano sintático}

A sintática representa o estudo das relações formais dos signos uns com os outros (MORRIS, 1938, p.6). Também chamada de plano lógico, retira como estrutura a relação signo-signo, tomando a proposição, bem como as relações intra e interproposicionais retrovertidas sobre si mesmas (MOUSSALLEM, 2014, p.158).

É esse campo semiótico que se debruça sobre o material bruto de trabalho de qualquer intérprete, escrutinando os signos e suas inter-relações, permitindo que o encadeamento de símbolos, decorrentes de relações lógicas, encaminhem o intérprete, com a compreensão adequada, a uma corrente de ideias.

\footnotetext{
${ }^{12}$ Clarice Von Oertzen de Araujo (2014, p.128) expõe o contexto em que se deu a publicação do trabalho seminal de Charles William Morris: "A segmentação dos processos semióticos ou da semiose (ação ou efeito gerado pelos signos) em três aspectos ou dimensões que podem ser abstraídos para o propósito de serem estudos isoladamente, e a denominação dos planos de investigação em 'sintático', 'semântico' e 'pragmático' foi inicialmente proposta em 1938, por Charles William Morris (1901-1979), ao elaborar uma monografia (Fundations of the Theory of Signs) que deveria compor a International Encyclopedia of United Science, publicação integrante de um extenso projeto de unificação das ciências, o que era um ideal fundamental do positivismo lógico".
} 
O primeiro e inevitável passo a todo sujeito cognoscente é justamente se aventurar, consciente ou não, nos aspectos sintáticos da linguagem. É o estudo das letras, que, organizadas nas formas devidas, constituem palavras, as quais têm funções variadas, ora servindo como qualificadoras de outras palavras, ora indicando o sentido de ação, e tantas outras existentes na complexa e vasta estruturação linguística, que conformam o texto bruto a ser comunicado e interpretado pelo sujeito receptor, gerando assim uma comunicação intersubjetiva.

A sintaxe se compõe tanto de a) um conjunto de signos, como de b) um conjunto de regras. As regras, por sua vez, subdividem-se em regras de formação, que indicam como combinar signos elementares, e regras de derivação, ${ }^{13}$ que permitem gerar novas expressões a partir de outras já construídas (WARAT, 1995, p.40).

Trazendo a sintática, que possui a lógica como forte instrumento, para o campo jurídico, temos a análise das relações estruturais do sistema e da norma jurídica (CARVALHO AT, 2013, p.169).

\subsubsection{Plano semântico}

Com a semântica, o segundo plano semiótico, tem-se a busca pela significação dos signos visitados e escrutinados na sua dimensão sintática (semântica pressupõe a sintaxe).

Segundo Charles W. Morris (1938, p.24), a dimensão semântica de um signo somente existe caso se verifiquem regras semânticas ("semantical rules"), pré-formuladas ou não, que determinem sua aplicabilidade para certas situações e sobre específicas condições.

A análise da dimensão semântica reside justamente em obter a compreensão das situações de aplicabilidade dos signos e das condições nas quais se determina essa aplicabilidade. A significação buscada não é, pois, desprovida de limites.

Dizer que se busca uma significação por meio da semântica, inicialmente indicava a busca pela correspondência fática, isto é, o significado das palavras remeteria aos objetos, ações humanas, acontecimentos naturais etc., enfim, objetos de comprovação empírica. No entanto, a experiência não necessariamente garantirá a ocorrência do fato nem assegurará a verdade sobre a asserção.

13 Como aponta Maria Helena Diniz (2009, p.167), um enunciado que não segue tais regras (formação e derivação) não teria sentido sob o ponto de vista sintático. 
Melhor, pois, a conclusão de que o significado se reporta a um ente ideal, ou seja, a palavra remete ao conceito (AFTALIÓN; VILANOVA; RAFFO, 2004, p.86) e não a fatos/objetos tidos como reais. Com as considerações da girada linguística, não há correspondência entre palavras e objetos. O significado é nada mais que outro significante, já que as significações do vocábulo dependem do vínculo com outras palavras (TOMÉ, 2005, p.3-4).

Ao se arriscar no plano semântico na dimensão jurídica é que se possibilita o estudo dos conteúdos significativos atribuídos aos símbolos positivados, lidando com problemas de vaguidade, ambiguidade e carga valorativa das palavras, estabelecendo-se a ponte que conecta a linguagem normativa à conduta intersubjetiva que ela regula (CARVALHO AT, 2013, p.169).

É no campo semântico, da construção das significações, que se procura restringir o campo de atuação do intérprete "para impedir eventuais construções desarrazoadas, baseadas em suposições abstratas, ou até com o intuito de induzir o destinatário do argumento em erro" (VIANNA, 2010, p.121). É então que emergem significações próprias a determinados institutos jurídicos, partindo-se de uma linguagem artificial que delimite e mitigue entendimentos díspares, facilitando a compreensão jurídica (VIANNA, 2010, p.121).

Ainda sobre a questão, interessantes as lucubrações de Riccardo Guastini (2005, p.51), que dispõe sobre dois modos diferentes de representar a semântica em um enunciado. O primeiro seria para fazer entender que para esse enunciado convergem ou não os valores de verdade (verdadeiro ou falso); o segundo, referir-se-ia ao entendimento de que esse enunciado é provido ou não de referência.

Em relação ao primeiro entendimento, o autor indica que há uma diferença semântica irredutível entre o discurso descritivo e o prescritivo, pois, enquanto aos enunciados descritivos convergem os valores de verdade, aos prescritivos - típicos da linguagem do direito positivado - isso não ocorre absolutamente (GUASTINI, 2005, p.51). Logo, nesse sentido, para o autor genovês, poder-se-ia falar que o enunciado prescritivo não possui semântica alguma.

Já no que concerne ao segundo ponto de vista, não parece haver uma diferença tão gritante, uma vez que o discurso prescritivo, tal qual o descritivo, também possui uma referência, devendo se relatar a sujeitos e comportamentos (GUASTINI, 2005, p.52). 


\subsubsection{Plano pragmático}

No derradeiro plano semiótico, a pragmática repousa na ciência da relação entre os signos e os intérpretes, ${ }^{14}$ versando, portanto, sobre os fenômenos psicológicos, biológicos e sociológicos que ocorrem no funcionamento dos signos (MORRIS, 1938, p.30).

É nessa interação entre signos e interlocutores, de que cuida a pragmática, que reside sua problemática central, que gira em torno dos modos de significar, usos e/ou funções da linguagem. A semiótica trabalha, então, com a ideia de fatores intencionais dos interlocutores que provocam alterações nas relações designativa-denotativa dos significados dos signos (WARAT, 1995, p.46).

Especialmente na pragmática - mas não só - emerge a máxima relevância do contexto, já que é o habitat do intérprete e dos signos que será capaz de remodelar prévias construções semânticas, bem como permitirá que elaborações iniciais sejam realizadas.

Tem-se como adequado compreender contexto na sua dimensão mais ampla, tratada por diversos linguistas, com forte influência de Eugenio Coseriu. Assim, contexto poderia ser dividido em verbal, que se refere às relações do signo com os demais signos da língua, e extraverbal, como sendo o conjunto de circunstâncias não linguísticas que se percebem diretamente ou são conhecidas pelo emissor da mensagem, havendo aqui, então, contextos físico (as coisas que estão à vista ou às quais um signo se adere), histórico (a situação histórica conhecida pelos interlocutores), cultural (a tradição cultural de uma comunidade), prático ou ocasional (a particular conjuntura objetiva ou subjetiva que ocorre no discurso), empírico (objetos e estados de coisas de conhecimentos dos interlocutores) e natural (todos os conceitos empíricos possíveis) (VIDAL, 1993, p.35-36).

É por meio dessas interações internas e externas oriundas do contexto, que moldam as significações, que a pragmática se desenvolve, mostrando que a interpretação não é algo estanque e definitivo.

A técnica semiótica aplicada ao Direito positivo, por meio do plano pragmático, permite que se observe o modo como os sujeitos se utilizam da linguagem jurídica para implantar os valores desejados socialmente, investigando-se o manuseio dos textos jurídicos pelos tribunais, ademais de questões acerca da criação e aplicação de normas jurídicas (CARVALHO AT, 2013, p.169-170).

\footnotetext{
14 Tratando de questão próxima, Charles S. Pierce (2005, p.284) escreve que a doutrina a qual chama de pragmatismo indica a teoria que propugna que o teor racional de uma palavra ou outra expressão linguística reside em sua concebível influência sobre a conduta da vida.
} 


\subsection{Construtivismo Lógico-Semântico e Teoria Comunicacional do Direito}

A tomada da semiótica por método de aproximação ao objeto de estudo, como aponta Tárek Moysés Moussallem (2011, p.244), levou a construção de pensamentos confluentes em relação ao Direito, surgindo a escola do Construtivismo Lógico-Semântico no Brasil e a Teoria Comunicacional do Direito na Espanha.

No que tange à primeira, podemos atribuí-la aos trabalhos realizados por Lourival Villanova e Paulo de Barros Carvalho. O segundo (2014, p.6) narra a origem do termo descrevendo pergunta que realizara ao primeiro e cuja resposta é digna de reprodução:

Certo dia, perguntando como conviria definir sua atitude jurídico-filosófica e o tipo de trabalho que vinha desenvolvendo, respondeu-me que poderíamos perfeitamente chamá-lo de "construtivismo". Não segundo o modelo do "construtivismo ético", todavia, agregando ao nome o adjetivo composto "lógico-semântico", pois, afinal de contas, todo o empenho estaria voltado a cercar os termos do discurso, para outorga-lhes a firmeza necessária (e possível, naturalmente), tendo em vista a coerência e o rigor da mensagem comunicativa. Isso não significa, porém, relegar o quadro das investigações pragmáticas a nível secundário. Expressa tão somente uma opção metodológica. Melhor seria até dizer que a proposta lógico-semântica aparece como contribuição para um estudo semiótico do discurso.

O construtivismo lógico-semântico pode ser compreendido tanto como a Escola Epistemológica do Direito, como também o método que é por ela empregado. Uma de suas mais fiéis adeptas, Aurora Tomazini de Carvalho (2014, p.15), esclarece que a proposta desse construtivismo é estudar o Direito dentro da concepção da Filosofia da Linguagem e, partindo desse referencial, amarra lógica e semanticamente suas proposições, de modo a construir seu objeto.

De sorte equivalente, erigiu-se na Espanha o desenvolvimento realizado por Gregorio Robles da chamada Teoria Comunicacional do Direito. Essa se apoia no evidente fato de que o Direito só é possível mediante palavras e se manifesta por meio da linguagem (LLANO, 2011, p.83).

Segundo nos informa Gregorio Robles, "a teoria comunicacional do direito, como qualquer outra concepção, é assim mesmo perspectiva. Contempla sua matéria - o fenômeno jurídico - desde uma perspectiva determinada: a comunicação humana" ${ }^{15}$

\footnotetext{
15 Tradução de: "[...] la teoria comunicacional del derecho, como cualquier outra concepción, es asimismo perspectiva. Contempla su materia - el fenómeno jurídico - desde una perspectiva determinada: la comunicación humana" (ROBLES, 2011, p.7).
} 
Como esclarecido por uma de suas maiores referências, Paulo de Barros Carvalho (2014, p.6), o construtivismo possui uma relação muito íntima com a Teoria Comunicacional do Direito, muito embora esta tenha uma abrangência maior e uma concepção mais filosófica, ao passo que o primeiro constitui muito mais um método de trabalho. Entretanto, ambos têm como premissa fundante que a linguagem é constitutiva da realidade.

\section{A LINGUAGEM E O DIREITO ADMINISTRATIVO}

Não obstante a percepção da importância fundante da linguagem nos termos trazidos pelo giro-linguístico, sentida por diversas áreas do conhecimento, há que se trazer à colação a visão de Lênio Streck (1999, p.48), segundo a qual a virada linguística não obteve a devida recepção filosófica e hermenêutica no campo jurídico em solo brasileiro. Para o autor, os juristas brasileiros ainda não se deram conta de que Direito é linguagem e como tal deverá ser considerado em tudo e por tudo como linguagem.

Evidentemente que a consideração supra possui suas exceções, tendo a linha filosófica que encara o Direito como linguagem ganhado adeptos em alguns setores dos estudos jurídicos ${ }^{16}$ no Brasil.

Os estudos pertinentes ao ramo do Direito Administrativo ${ }^{17}$, contudo, parecem não se enquadrar nessa exceção, sendo praticamente inexistentes monografias jurídicas dessa seara que foquem suas reflexões levando em conta a linguagem do Direito como elemento imprescindível - pelo menos não de maneira expressa.

Apesar dessa lacuna doutrinária associativa entre o Direito Administrativo e a linguagem de maneira clara e declarada, fato é que, trabalhando-se o Direito como linguagem, como aqui se faz, por evidente que o Direito Administrativo não poderia se situar fora dessa perspectiva.

Sem qualquer pretensão de esgotamento da questão, é possível iluminar pontos do Direito Administrativo nos quais um estudo por intermédio da filosofia da linguagem

\footnotetext{
16 Talvez o ramo que melhor tenha conseguido se estruturar com essa abordagem tenha sido o Direito Tributário, por intermédio das lições de Paulo de Barros Carvalho, com o chamado Construtivismo LógicoSemântico.

17 "Este sentimento da necessidade de uma pesquisa constante, até mesmo "diferenciada", é observado quando se trabalha, dentre tantos, o estudo do Direito, mas em específico o ramo do Direito Administrativo. Este conjunto de normas semelhantes, que trabalham questões atinentes em especial à Administração Pública, tende a ser desenvolvido no Brasil de uma maneira conservadora, que, embora muito bem construído e estruturado, por vezes possui elementos que ainda, como dito, merecem um aporte científico destacado e desvinculado da forma de pesquisa existente até então" (CABRAL, 2015, p.137).
} 
confere uma compreensão metodologicamente coerente e oferece novos contornos às lições dogmáticas clássicas.

De início, de maneira superficial, pode-se mencionar o estudo dos atos administrativos, entendidos como uma manifestação da vontade funcional (JUSTEN FILHO, 2012, p.343) ou, colocado de outra maneira mais completa, uma "declaração do Estado ou de quem o represente, que produz efeitos jurídicos imediatos, com observância da lei, sob o regime jurídico de direito público e sujeita a controle pelo Poder Judiciário" (DI PIETRO, 2017, p.237). Vê-se, desde logo, que a definição consagrada de ato administrativo remete de maneira clara a um ato de linguagem ("declaração"), não podendo, pois, ser investigado de maneira desassociada desta constatação.

Da mesma forma, quando se atesta que, como regra, os atos administrativos são praticados de forma escrita, registrados e publicados (CARVALHO FILHO, 2010, p.122), novamente se está a indicar a utilização de signos próprias para a emissão da linguagem.

O estudo dos princípios administrativos, tema da mais alta relevância aos estudos do Direito (mandamentos nucleares de um sistema, na célebre constatação de Celso Antônio Bandeira de Mello (2017, p.54)), pode ser aprimorado levando-se em consideração os planos semióticos ${ }^{18}$. Ao invés de se atribuir conteúdos aos denominados princípios aplicáveis à Administração Pública de maneira arbitrária, indicativo de meras preferência subjetivas dos autores, como por vezes encontramos aqui e acolá, um estudo sistemático, levando-se em consideração o seu plano sintático (quais os textos - e sua consequente estruturação - que fazem menção a essa princípios), semântico (qual a significação atribuída as palavras relacionadas a esse princípio dentro dos limites histórico-culturais e do contexto investigado) e pragmático (qual o peso simbólico desse princípio e como vem sendo aplicado pelos Tribunais e demais agentes competentes), possui o condão de conferir interpretações com um grau maior de objetividade (sem afastar a subjetividade inerente da interpretação, relacionada às pré-compreensões do intérprete) e segurança, em detrimento de construções rasas ou hiperabrangentes que em nada auxiliam o aplicador.

Trazendo uma questão mais pontual, é pelo estudo da linguagem que se poderia sugerir um caminho à interpretação, por exemplo, do artigo $142, \S 2^{\circ}$, da Lei ${ }^{\circ} 8.112 / 90$, que ao tratar sobre o regime jurídico dos servidores públicos federais, prescreve que "os prazos

\footnotetext{
${ }^{18}$ Confira-se um dos pouquíssimos trabalhos realizados nessa perspectiva da filosofia da linguagem na tese escrita acerca do conteúdo jurídico da eficiência administrativa na perspectiva do construtivismo lógicosemântico (CABRAL, 2017).
} 
de prescrição previstos na lei penal aplicam-se às infrações disciplinares capituladas também como crime".

A questão nodal do artigo invocado reside em saber quando poderia ser considerado uma conduta como crime para fins de contagem prescricional da infração disciplinar. Veja que a Controladoria-Geral da União editou o Enunciado $\mathrm{n}^{\circ} 05$, o qual dispõe que "para aplicação de prazo prescricional, nos moldes do $\S 2^{\circ}$ do art. 142 da lei 8.112/90, não é necessário o início da persecução penal". Ou seja, segundo o órgão de controle, a análise da tipificação da conduta levada a efeito pelo agente público como crime pode ser realizada pela própria autoridade administrativa responsável pelo processo administrativo disciplinar.

De maneira distinta, o Superior Tribunal de Justiça já produziu decisões - não chegando a ser a posição unânime da Corte - indicando que "a mera presença de indícios de prática de crime sem a devida apuração nem formulação de denúncia, obsta a aplicação do regramento da legislação penal para fins de prescrição" (STJ, RMS nº 14.420/RS - 2002).

Sem a intenção de resolver o mérito desta questão, mas somente com o propósito de demonstrar a utilização da linguagem na construção interpretativa das normas administrativas, temos que na linha do construtivismo lógico-semântico haveria que se falar em crime não pelo mero acontecimento no mundo social ${ }^{19}$, mas sim com a edição de ato por meio da linguagem competente. Nos parece que, na linha da decisão do STJ - ainda que não tendo chegado a essa conclusão pela metodologia aqui empregada -, realizando uma análise estruturada do ordenamento jurídico brasileiro, a linguagem adequada para o surgimento de um crime no mundo jurídico dependeria de atos como uma denúncia ofertada pelo órgão competente ou uma decisão judicial condenatória, não sendo a autoridade administrativa competente para a edição deste ato comunicacional e constitutivo do crime para o campo do jurídico.

Outro ponto a ser considerado, talvez um dos mais antigos e ainda hoje sem uma solução pacificada, repousa no controle da discricionaridade administrativa, em particular atenção aos limites do controle (com ênfase ao controle judicial, mas não só ele) dos atos administrativos.

Se muito já se escreveu sobre a questão, podendo-se mencionar as referenciais obras de Celso Antônio Bandeira de Mello (1992), Miguel Seabra Fagundes ou José Cretella

\footnotetext{
${ }^{19}$ É com essa visão que Aurora Tomazini de Carvalho (2013, p.137) discorre que o plano do direito positivo é sintaticamente fechado, constituindo-se de uma linguagem própria, a qual não se confunde com a linguagem social, e só permite o ingresso de elementos externos quando relatados no seu próprio código jurídico. É necessária a transformação daquela linguagem social em jurídica para que o evento possa ingressar no sistema.
} 
Júnior (1965), certo é que compreender quais os limites para que o Poder Judiciário possa adentrar na análise dos atos administrativos, com destaque na questão do seu mérito, relaciona-se com a compreensão das questões da linguagem.

O pernicioso ativismo judicial, entendido aqui como a atuação dos magistrados além do que lhes é juridicamente autorizado constitucionalmente, ancora-se, em parte, na desconsideração dos limites lógico-semânticos do texto jurídico positivado, aliado ao contexto $^{20}$ da situação concreta sob análise.

Quando determinado juiz atribui, de maneira arbitrária, que onde se está escrito "A" deve-se ler "B", alterando as significações histórica e culturalemnte dadas aquele termo sintático, há um evidente extrapolamento da sua atuação judicial, pois, repita-se, um primeiro e insuperável limite na teoria da decisão judicial é (deve-ser) a linguagem.

Umbilicalmente conectado a esse controle está o ponto dos conceitos jurídicos indeterminados, elemento essencial ao Direito Administrativo (em realidade, ao Direito como um todo). Construir as normas jurídicas pertinentes a textos que se valem desses termos, os quais “encerram valorações, isto é, sentidos axiológicos, jurídicos" (DI PIETRO, 1991, p.48), demanda a verificação das pré-compreensões ${ }^{21}$ daqueles termos aliadas ao contexto fático, jurídico e linguístico no qual se situam, evidenciando, novamente, que o administrativista que desconsidera o Direito como linguagem parece estar fadado a interpretações dúbias e equivocadas.

Embora invocações de termos como interesse público, moralidade administrativa, eficiência administrativa, probidade, dentre outros tão frequentes no dia-a-dia dos administrativistas possam ser, por vezes, polissêmicos, é certo que haverá limites fora das zonas de incerteza linguística que não permitem qualquer interpretação aleatória e ao gosto do intérprete.

Não se pode deixar de considerar também o aspecto probatório nos processos administrativos, em especial nos de cunho disciplinar.

Sobre as provas, pertinente o exame feito por Fabiana Del Padre Tomé (2017), por se alinhar precisamente à linha do construtivismo lógico-semântico. Para a autora, como os

\footnotetext{
20 "É tolice afirmar categoricamente que conhecemos o sentido de uma palavra antes de a termos utilizado em alguma elocução. O que podemos conhecer com antecedência é apenas aproximadamente o que ela significa. Depois de empregarmos, e interpretarmos o que foi dito à luz do contexto físico e verbal, agiremos de acordo com a interpretação. [...] Fica bem claro, então, que ignorar contextos, em qualquer caso de interpretação, é um procedimento bastante insensato" (HAYAKAWA, 1977, p.71-72).

${ }^{21}$ A nossa vivência depende da cultura, da linguagem na qual estamos inseridos. "Assim entendido, o mundo é um conjunto de significações, de saberes, de valores, de gostos, de certezas: uma pré-interpretação ou uma ‘pré-compreensão', como chamava Heidegger” (SCAVINO, 2014, p.19).
} 
acontecimentos físicos exaurem-se no tempo e no espaço, sendo impossível seu acesso, fazse necessário ao homem utilizar enunciados linguísticos para constituir os fatos com que pretenda entrar em contato. Afinal, um evento não prova nada. É o homem, valendo-se de relatos e de sua interpretação, que faz a prova. Por essa razão, os eventos não integram o universo jurídico ou os autos processuais. "O que integra o processo são sempre fatos: enunciados que declaram ter ocorrido uma alteração no plano físico-social, constituindo a facticidade jurídica".

As reflexões pessoais do agente, bem como os acontecimentos do mundo fenomênico, não servem como prova, devendo ser instrumentalizados pelos enunciados linguísticos autorizados (seja quanto ao conteúdo, seja quanto à forma de se constituirem) pelo Direito (documentos, testemunhos, perícias etc.), para servirem como mecanismo probatório adequado.

Qualquer agente administrativo que se proponha a julgar um processo administrativo disciplinar somente poderá fazê-lo por intermédio da avaliação probatória de cada caso concreto. A declaração de que determinado ato ocorreu de uma forma ou de outra não depende dos eventos físicos que o permeiam, mas sim dos relatos desses acontecimentos, que, somente após relatados, configuram-se fatos. Sem os relatos (fatos), ainda que os acontecimentos físicos pudessem direcionar a um sentido oposto, não há como invalidar um ato, justamente pela deficiência de provas.

E por que não trabalhar as normas jurídicas relacionadas à disciplina administrativa por meio de uma análise sintática estrutural, valendo-se, por exemplo, da regra matriz?

Dita regra, tida como matriz de incidência, elaborada por Paulo de Barros Carvalho (2012, p.135), corresponde à organização do núcleo lógico-estrutural da norma padrão (juízo hipotético-condicional) indicada pela conjunção de seus elementos indicativos. Tais elementos se dividem no descritor da norma (também denominado de hipótese, antecedente ou suposto), no qual se encontrarão as diretrizes para identificação de eventos que portem expressão econômica, havendo aí um critério material (comportamento de uma pessoa), condicionado no tempo e espaço (critérios temporal e espacial). Ademais, haverá um prescritor (consequente), no qual se encontrará um critério pessoal (sujeito ativo e passivo) e um critério quantitativo (alíquota e base de calculo). 
Calha tracejar que a construção de Paulo de Barros Carvalho foi desenvolvida tendo em vista especialmente a norma tributária, ${ }^{22}$ razão pela qual a presença no consequente normativo do critério quantitativo formado por alíquota e base de cálculo figura para ele como de suma importância.

Apesar disso, as conclusões advindas da regra matriz se referem à estruturação de uma norma padrão, afeta a qualquer ramo jurídico, porquanto se conformam na estrutura hipotético-condicional, conectada por um modal deôntico. Ou seja, é possível realizar uma análise apurada das normas administrativas decompondo-as, por meio de um estudo linguístico de signos, em hipótese e consequente, de modo a compreendê-las melhor, facilitando a detecção de vícios em seus elementos ou mesmo uma possível inconstitucionalidade.

Um dos poucos juristas que busca trabalhar o Direito Administrativo ciente dos limites da linguagem é Ricardo Marcondes Martins. Este administrativista traz à tona uma outra importante questão afeta ao Direito Administrativo e os signos linguísticos, referindose às contrafações administrativas.

Explica o autor que contrafação deve ser encarada no sentido de disfarce, simulação, fingimento e, numa acepção anfibológica, indica tanto o ato que efetua a simulação, como o efeito dela. Esclarece que a palavra foi invocada no Direito Administrativo por Celso Antônio Bandeira de Mello ao se referir às permissões administrativas. Assim, sintetiza que

Contrafação administrativa consiste no emprego de um conceito para uma situação incompatível com o regime jurídico a ele associado. Nela, referência, denotação ou extensão pretendidas são incompatíveis com o sentido, conotação ou intensão. Não há, na contrafação, apenas um emprego equivocado: ocorre uma fraude, o emprego do conceito errado tem por efeito mascarar, disfarçar, esconder o conceito correto e o regime jurídico respectivo (MARTINS, 2016, p.143).

Sem adentrar nos meandros do estudo das contrafações administrativas, o que se quer aqui indicar é que essa perniciosa ${ }^{23}$ figura surge, como apontado na definição alhures, da incompatibilidade entre conotação e denotação, questões ínsitas ao estudo linguístico. Como aponta Ricardo Marcondes Martins (2016, p.121), as contrafações decorrem de duas

\footnotetext{
22 Tanto é assim que a gênese da regra matriz de incidência pode ser encontrada em sua tese de doutorado, ainda que não utilizando a nomenclatura "regra matriz", que desencadeou a obra "Teoria da norma tributária", indicando o escopo principal do autor em laborar essencialmente, nesse primeiro momento, no âmbito tributário.

23 "As contrafações administrativas configuram um grave problema jurídico tendo em vista que, regra geral, encontram forte apoio doutrinário e jurisprudencial. $\mathrm{O}$ apoio doutrinário explica-se pelo caráter operativo da ciência do direito. $\mathrm{O}$ apoio jurisprudencial pela influência da doutrina sobre a jurisprudência. Concluiu-se que ambos os fatores não são suficientes para legitimar as contrafações" (MARTINS, 2016, p.144).
} 
situações, quais sejam: i) o legislador emprega o signo num significado diverso do significado corrente na linguagem jurídica; ii) o legislador emprega o signo em conformidade com significado corrente, mas numa situação incompatível com o regime jurídico relativo a esse significado.

Esses singelos exemplos e referências, que poderiam ser multiplicados a perder de vista, simplesmente servem de exemplificação para indicar que o Direito Administraivo também pode, ou melhor, deve ser explorado por meio dos instrumentos linguísticos, sendo que essa abordagem somente gera ganhos hermenêuticos aos administrativistas. Afinal, em particular nas relações do Estado com os administrados, próprias do Direito Administrativo, deve-se lembrar que "o Imperador não está acima dos gramáticos". ${ }^{24}$

\section{CONSIDERAÇÕES FINAIS}

A alternância de focos e métodos de análise é prática sempre saudável para o desenvolvimento científico do conhecimento, desde que não implique na realização de uma mixórdia metodológica.

É nesta toada que se buscou realizar aqui uma abordagem que ainda hoje foge do padrão da pesquisa nas disciplinas jurídicas, em especial no Direito Administrativo, que é o estudo relacional entre Direito e linguagem.

Deste breve e provocativo artigo, pode-se elencar de maneira organizada as seguintes conclusões e análises:

1. O movimento giro-linguístico proporcionou uma mudança de paradigma na teoria do conhecimento, que não mais representa uma relação entre sujeito e objeto, mas sim entre linguagens.

2. A linguagem na concepção giro-linguística constitui a própria realidade.

\footnotetext{
${ }^{24}$ Referida frase decorre do relato de que no Concílio de Constança, celebrado na cidade alemã de mesmo nome, entre os anos de 1414 e 1418, o Sacro Imperador Romano-Germânico, Sigismundo I, em seu discurso inaugural dirigido aos eclesiásticos, utilizou como feminino o substantivo neutro "schisma". Dentre os presentes, o Cardeal Placentio, ao notar o equívoco do Imperador, pontuou que: a expressão estava gramaticalmente incorreta, pois schisma é de gênero neutro (Domine, ista locutio tua est parum grammatica, cum schisma sit generis neutrius). Irritado com a correção, Sigismundo I vociferou que ele era o Imperador e que, por ser o senhor das terras, dos homens e das leis, de igual maneira poderia utilizar as palavras como bem lhe aprouvesse. Em resposta, Placentio simplesmente apontou que "O Imperador não está acima dos gramáticos!” (Caesar non est supra grammaticos) (FUMAGALLI, 1934, p.503-504).
} 
3. O Direito positivo, por ser constituído de linguagem, pode ser encarado como um conjunto de símbolos artificiais que exprimem mensagens prescritivas a seus receptores.

4. Uma maneira de estudar o Direito, levando-se em consideração sua formação pela linguagem, é pelo instrumento linguístico da semiótica, que divide o plano comunicacional em três campos: o sintático ou lógico; o semântico; e o pragmático.

5. A sintática representa o estudo das relações formais dos signos uns com os outros. Para o Direito, permite a análise das relações estruturais do sistema e da norma jurídica.

6. A semântica trata da significação dos signos, referindo-se à compreensão do conteúdo destes e suas situações de aplicabilidade. Seu estudo no plano jurídico possibilita a investigação dos conteúdos significativos atribuídos aos símbolos positivados, lidando com problemas de vaguidade, ambiguidade e carga valorativa das palavras.

7. A compreensão do conteúdo sempre pressupõe o contexto, que concerne à pesquisa externa ao texto, buscando-se fatores que podem influenciar as relações de significações.

8. A pragmática diz respeito à relação dos signos com os intérpretes, bem como à demonstração das funções que o discurso comunicativo possui em relação aos comportamentos dos emissores/interlocutores. Para o Direito, a pragmática pesquisa o manuseio dos textos jurídicos pelos agentes competentes, bem como questões acerca de aplicação e criação das normas jurídicas.

9. O Direito Administrativo pode aproveitar em muito dessa perspectiva linguística, que confere aos intérpretes novos focos de percepção sobre uma temática, bem como fornece critérios mais objetivos de análise aos juristas.

10. Questões como o controle judicial dos atos administrativos, análise de vícios por meio da utlização da regra matriz, verificação das contrafações administrativas, questão probatória nos processos administrativos, construção do conteúdo jurídico dos princípios jurídicos são só alguns singelos exemplos da utilidade - e sua inter-relação - da linguagem com o Direito Administrativo.

\section{REFERÊNCIAS}

AFTALIÓN, Enrique R.; VILANOVA, José; RAFFO, Julio. Introducción al derecho. 4.ed. Buenos Aires: Abeledo-Perrot, 2004.

ARAUJO, Clarice Von Oertzen de. Semiótica do direito. São Paulo: Quartier Latin, 2005. 
Semiótica e investigação do direito. In: CARVALHO, Aurora Tomazini de (Org.).

Construtivismo Lógico-Semântico. São Paulo: Noeses, 2014. v. I. p.121-154.

AUROUX, Sylvain. A filosofia da linguagem. Tradução José Horta Nunes. Campinas: Editora da Unicamp, 1998.

BANDEIRA DE MELLO, Celso Antônio. Curso de direito administrativo. 33.ed. São Paulo: Malheiros, 2017.

Discricionariedade e controle jurisdicional. São Paulo: Malheiros, 1992.

CABRAL, Flávio Garcia. Características do princípio da moralidade administrativa como valor. Revista da AGU, a.14, n.02, p.135-160, abr./jun. 2015.

Conteúdo jurídico da eficiência administrativa: uma análise lógico-semântica e pragmática. 2017. 276 f. Tese (Doutorado) - Curso de Direito, Pontifícia Universidade Católica de São Paulo, São Paulo, 2017.

CARVALHO, Aurora Tomazini de. Construtivismo lógico-semântico como método de trabalho na elaboração jurídica. In: CARVALHO, Aurora Tomazini de (Org.).

Construtivismo Lógico-Semântico. São Paulo: Noeses, 2014. v.I. p.13-40.

Curso de teoria geral do direito: o construtivismo lógico-semântico. 3.ed. São Paulo: Noeses, 2013.

CARVALHO, Paulo de Barros. Algo sobre o construtivismo lógico-semântico. In: CARVALHO, Aurora Tomazini de (Org.). Construtivismo Lógico-Semântico. São Paulo: Noeses, 2014. v.I. p.3-12.

Direito Tributário, Linguagem e Método. São Paulo: Noeses, 2013.

2012.

Direito tributário: fundamentos jurídicos de incidência. 9.ed. São Paulo: Saraiva,

CARVALHO FILHO, José dos Santos. Manual de direito administrativo. 23.ed. Rio de Janeiro: Lumen Juris, 2010.

COLARES, Virgínia. Apresentação: por que a Linguagem interessa ao Direito? In: COLARES, Virgínia (Org.). Linguagem e direito. Recife: Ed. Universitária da UFPE, 2010. p.9-22.

COSTA, Cláudio. Filosofia da linguagem. 3.ed. Rio de Janeiro: Jorge Zahar, 2007.

CRETELLA JÚNIOR, José. O mérito do ato administrativo. Revista de Direito Administrativo - RDA, Rio de Janeiro, v.79, p.23-37, 1965.

DI PIETRO, Maria Sylvia Zanella. Direito administrativo. 30.ed. Rio de Janeiro: Forense, 2017.

. Discricionariedade Administrativa na Constituição de 1988. São Paulo: Atlas, 
1991.

DINIZ, Maria Helena. Compêndio de introdução à ciência do direito. 20.ed. São Paulo: Saraiva, 2009.

ECO, Umberto. A theory of semiotics. Bloomington: Indiana University Press, 1979.

FAGUNDES, Miguel Seabra. O contrôle dos atos administrativos pelo Poder Judiciário. 4.ed. Rio de Janeiro: Forense, 1967.

FERRAZ JÚNIOR, Tercio Sampaio. Teoria da norma jurídica: ensaio de pragmática da comunicação normativa. 4.ed. Rio de Janeiro: Forense, 2006.

FLUSSER, Vilém. Língua e realidade. São Paulo: Annablume, 2004.

FOUCAULT, Michel. As palavras e as coisas: uma arqueologia das ciências humanas. 8.ed. Tradução Salma Tannus Muchail. São Paulo: Martins Fontes, 1999.

FUMAGALLI, Giuseppe. Chi L’'ha Detto? 8 ed., Milano: Ulrico Hoepli, 1934.

GADAMER, Hans-Georg. Verdad y metodo II. Tradução Manuel Olasagasti. Salamanca: Ediciones Sígueme, 1998.

GUASTINI, Riccardo. Das fontes às normas. Tradução Edson Bini. São Paulo: Quartier Latin, 2005.

HABERMAS, Jürgen. O discurso filosófico da modernidade: doze lições. Tradução Luiz Sérgio Repa; Rodnei Nascimento. São Paulo: Martins Fontes, 2000.

HAYAKAWA, S.I. A linguagem no pensamento e na ação. 3.ed. Tradução Jane A. Perricari. São Paulo: Livraria Pioneira, 1977.

IVO, Gabriel. Norma jurídica: produção e controle. São Paulo: Noeses, 2006.

JUSTEN FILHO, Marçal. Curso de direito administrativo. 8.ed. Belo Horizonte: Fórum, 2012.

LINS, Robson Maia. Considerações sobre o conceito de norma jurídica e pragmática da comunicação na decisão judicial na jurisprudência do Supremo Tribunal Federal. In: CARVAlHO, Aurora Tomazini de (Org.). Construtivismo Lógico-Semântico. São Paulo: Noeses, 2014. v.I. p.169-200.

LLANO, Fernando H. Experiencialismo jurídico y teoría comunicacional del derecho: dos concepciones globales del derecho. In: ROBLES, Gregorio; CARVALHO, Paulo de Barros (Coord.). Teoria comunicacional do direito: Diálogo entre Brasil e Espanha. São Paulo: Noeses, 2011. p.75-102.

MARTINS, Ricardo Marcondes. Teoria das contrafações administrativas. A\&C - Revista de Direito Administrativo \& Constitucional, Belo Horizonte, a. 16, n. 64, p. 115-148, abr./jun. 2016. 
MORRIS, Charles W. Foundations of the Theory of Signs. International Encyclopedia of Unified Sciences. Chicago, v.1, n.2, p.1-59, 1938.

MOUSSALLEM, Tárek Moysés. A enunciação e os enunciados: a performatividade do direito. In: ROBLES, Gregorio; CARVALHO, Paulo de Barros (Coord.). Teoria comunicacional do direito: Diálogo entre Brasil e Espanha. São Paulo: Noeses, 2011. p.243-264.

A lógica como técnica de análise do direito. In: CARVALHO, Aurora Tomazini de (Org.). Construtivismo Lógico-Semântico. São Paulo: Noeses, 2014. v.I. p.155-168.

PIERCE, Charles S. Semiótica. Tradução José Teixeira Coelho Neto. São Paulo: Perspectiva, 2005.

ROBLES, Gregorio. Perspectivismo textual y principio de relatividad sistémica en la teoría comunicacional del derecho. In: ROBLES, Gregorio; CARVALHO, Paulo de Barros (Coord.). Teoria comunicacional do direito: Diálogo entre Brasil e Espanha. São Paulo: Noeses, 2011. p.3-32.

SAUSSURE, Ferdinand de. Escritos sobre linguistica general. Tradução Clara Ubaldina Lorda Mur. Barcelona: Gedisa, 2004.

SCAVINO, Dardo. A filosofia atual: pensar sem certezas. Tradução Lucas Galvão de Britto. São Paulo: Noeses, 2014.

SOAMES, Scott. Philosophy of language. New Jersey: Princeton University Press, 2010.

STRECK, Lênio Luiz. Dicionário de hermenêutica: quarenta temas fundamentais da teoria do direito à luz da crítica hermenêutica do Direito. Belo Horizonte: Casa do Direito, 2017.

Hermenêutica jurídica e(m) crise. Porto Alegre: Livraria do Advogado, 1999.

TOMÉ, Fabiana Del Padre. A prova no direito tributário. São Paulo: Noeses, 2005.

Prova. In: Enciclopédia jurídica da PUC-SP. Celso Fernandes Campilongo, Alvaro de Azevedo Gonzaga e André Luiz Freire (coords.). Tomo: Teoria Geral e Filosofia do Direito. Celso Fernandes Campilongo, Alvaro de Azevedo Gonzaga, André Luiz Freire (coord. de tomo). 1. ed. São Paulo: Pontifícia Universidade Católica de São Paulo, 2017. Disponível em: https://enciclopediajuridica.pucsp.br/verbete/91/edicao-1/prova.

VIDAL, M. Victoria Escandell. Introducción a la pragmática. Madrid: Universidad Nacional de Educación a Distancia, 1993.

WARAT, Luis Alberto. O direito e sua linguagem. 2.ed. Porto Alegre: Sergio Antônio Fabris, 1995. 
WITTGENSTEIN, Ludwig. Investigações filosóficas. Tradução José Carlos Bruni. São Paulo: Nova Cultural Ltda, 1999.

Tractatus logico-philosophicus. Tradução José Arthur Giannotti. São Paulo: Editora da Universidade de São Paulo, 1968.

Trabalho recebido em 22 de fevereiro de 2019

Aceito em 05 de dezembro de 2020 